\title{
Synaptic Organization of the Neuronal Circuits of the Claustrum
}

\author{
Juhyun Kim, Chanel J. Matney, Richard H. Roth, and Solange P. Brown \\ Solomon H. Snyder Department of Neuroscience, Johns Hopkins University School of Medicine, Baltimore, Maryland 21205
}

The claustrum, a poorly understood subcortical structure located between the cortex and the striatum, forms widespread connections with almost all cortical areas, but the cellular organization of claustral circuits remains largely unknown. Based primarily on anatomical data, it has been proposed that the claustrum integrates activity across sensory modalities. However, the extent to which the synaptic organization of claustral circuits supports this integration is unclear. Here, we used paired whole-cell recordings and optogenetic approaches in mouse brain slices to determine the cellular organization of the claustrum. We found that unitary synaptic connections among claustrocortical $(\mathrm{ClaC})$ neurons were rare. In contrast, parvalbumin-positive (PV) inhibitory interneurons were highly interconnected with both chemical and electrical synapses. In addition, $\mathrm{ClaC}$ neurons and PV interneurons formed frequent synaptic connections. As suggested by anatomical data, we found that corticoclaustral afferents formed monosynaptic connections onto both ClaC neurons and PV interneurons. However, the responses to cortical input were comparatively stronger in PV interneurons. Consistent with this overall circuit organization, activation of corticoclaustral afferents generated monosynaptic excitatory responses as well as disynaptic inhibitory responses in $\mathrm{ClaC}$ neurons. These data indicate that recurrent excitatory circuits within the claustrum alone are unlikely to integrate across multiple sensory modalities. Rather, this cellular organization is typical of circuits sensitive to correlated inputs. Although single ClaC neurons may integrate corticoclaustral input from different cortical regions, these results are consistent with more recent proposals implicating the claustrum in detecting sensory novelty or in amplifying correlated cortical inputs to coordinate the activity of functionally related cortical regions.

Key words: channelrhodopsin-2; claustrocortical; claustrum; cortex; parvalbumin

\section{Significance Statement}

The function of the claustrum, a brain nucleus found in mammals, remains poorly understood. It has been proposed, based primarily on anatomical data, that claustral circuits play an integrative role and contribute to multimodal sensory integration. Here we show that the principal neurons of the claustrum, claustrocortical (ClaC) projection neurons, rarely form synaptic connections with one another and are unlikely to contribute to broad integration within the claustrum. We show that, although single $\mathrm{ClaC}$ neurons may integrate corticoclaustral inputs carrying information for different sensory modalities, the synaptic organization of $\mathrm{ClaC}$ neurons, local parvalbumin-positive interneurons within the claustrum, and cortical afferents is also consistent with recent proposals that the claustrum plays a role in detecting salient stimuli or amplifying correlated cortical inputs.

\section{Introduction}

The claustrum, a poorly understood subcortical structure found bilaterally in mammals, including humans, forms connections

Received Oct. 2, 2015; revised Nov. 19, 2015; accepted Nov. 29, 2015.

Author contributions: J.K. and S.P.B. designed research; J.K., C.J.M., R.H.R., and S.P.B. performed research; J.K. and S.P.B. analyzed data; J.K. and S.P.B. wrote the paper.

This work was supported by the National Institutes of Neurological Diseases (NS050274). J.K. was supported by a National Research Foundation of Korea fellowship (NRF-2011-357-E00005). C.J.M. was supported by a predoctoral fellowship from the National Science Foundation and by a National Institutes of Health training grant (5T32EY017203). S.P.B. is supported by a Klingenstein-Simons Fellowship in the Neurosciences and a National Alliance for Research on Schizophrenia and Depression Young Investigator Award from the Brain and Behavior Research Foundation. We thank E.M. Schulteis, A.E. Coye, B.A. Morris, and C.J. Pope for technical assistance; B.K. Harvey, the National Institute of Drug Abuse Optogenetics and Transgenic Technology Core, K. Deisseroth, and the Stanford Neuroscience Gene Vector and Virus Core for viral constructs; and S. Hestrin for Igor Pro routines. with almost all regions of the neocortex (Pearson et al., 1982; Sloniewski et al., 1986; Kowianski et al., 1999; Zingg et al., 2014; Milardi et al., 2015). Due in part to its challenging size and location in the brain, studies of the claustrum's functional properties have been limited. Based largely on its widespread anatomical connections with the cortex, it has been proposed that the system links diverse cortical regions and plays a role in multimodal sensory integration (Pearson et al., 1982; Ettlinger and Wilson, 1990;

\section{The authors declare no competing financial interests.}

Correspondence should be addressed to Solange Brown, Solomon H. Snyder Department of Neuroscience, Johns Hopkins School of Medicine, WBSB 906, 725 N. Wolfe Street, Baltimore, MD 21205. E-mail: spbrown@jhmi.edu. DOI:10.1523/JNEUROSCI.3643-15.2016

Copyright $\odot 2016$ the authors $\quad 0270-6474 / 16 / 360773-12 \$ 15.00 / 0$ 
Edelstein and Denaro, 2004; Crick and Koch, 2005). Functional studies in humans have also implicated the claustrum in crossmodal integration (Hadjikhani and Roland, 1998; Banati et al., 2000; Calvert, 2001; Naghavi et al., 2007). However, other studies argue against broad integration within this structure. Electrophysiological recordings in vivo, for example, indicate that neuronal responses in different regions of the claustrum are restricted to specific sensory modalities (Olson and Graybiel, 1980; Sherk and LeVay, 1981a, b; Remedios et al., 2010). Based on these data and more recent anatomical studies, it has been proposed that the claustrum instead generates transient responses to signal salient stimuli or coordinates the activity of functionally related cortical areas (Remedios et al., 2010, 2014; Smith et al., 2012; Smythies et al., 2012, 2014a,b; Mathur, 2014; Reser et al., 2014; Smith and Alloway, 2014; Goll et al., 2015).

One difficulty in understanding the function of the claustrum has been the paucity of data concerning the synaptic organization of claustral neural circuits. Although it has been proposed that intrinsic connections within the claustrum play a role in multimodal integration (Crick and Koch, 2005; Smythies et al., 2012, 2014b; Druga, 2014), the synaptic relationships of neurons within the claustrum are largely unknown. Large, spiny neurons within the claustrum that project to the cortex represent the claustrum's principal neurons (Brand, 1981; LeVay and Sherk, 1981; Braak and Braak, 1982; Druga, 2014). The claustrum is also notable for its dense plexus of parvalbumin-positive (PV) fibers formed by local aspiny neurons (Druga et al., 1993; Real et al., 2003; Hinova-Palova et al., 2007, 2014; Rahman and Baizer, 2007). Degeneration studies combined with electron microscopy suggest that $\mathrm{ClaC}$ neurons receive the majority of cortical input, although corticoclaustral axons also synapse onto aspiny neurons (Juraniec et al., 1971; LeVay and Sherk, 1981; Hinova-Palova et al., 1988). The synaptic relationships among neurons within the claustrum, however, remain unclear (Juraniec et al., 1971; LeVay and Sherk, 1981; Hinova-Palova et al., 2007; Smith and Alloway, 2010; Druga, 2014).

Here, by performing the first targeted recordings from identified claustral neurons, we sought to discover whether the cellular organization of claustral circuits supports integration within the claustrum. By combining cell-type identification, paired whole-cell patch-clamp recordings, and optogenetic approaches in mouse brain slices, we determined the cellular organization of the claustrum. We found that $\mathrm{ClaC}$ neurons were rarely synaptically connected with one another. In contrast, inhibitory PV neurons in the claustrum were highly interconnected with both chemical and electrical synapses. Furthermore, these PV neurons formed frequent unitary connections with $\mathrm{ClaC}$ neurons. We also found that corticoclaustral axons synapsed onto both $\mathrm{ClaC}$ principal neurons and PV neurons, consistent with anatomical studies. Optogenetic stimulation of corticoclaustral axons generated monosynaptic excitation as well as feedforward inhibition in $\mathrm{ClaC}$ neurons. Together, these data indicate that $\mathrm{ClaC}$ neurons are only weakly interconnected and are unlikely to integrate signals locally within the claustrum. The highly interconnected PV interneurons, the frequent connections between PV interneurons and $\mathrm{ClaC}$ neurons, and the feedforward inhibition elicited by cortical activation all suggest that the claustrum serves to detect correlated cortical inputs or to amplify synchronous cortical inputs to coordinate the activity of functionally related cortical regions (Bartos et al., 2007; Bruno, 2011).

\section{Materials and Methods}

All experiments were conducted in accordance with the procedures established by the Johns Hopkins Animal Care and Use Committee and followed the guidelines of the National Institutes of Health and the Society for Neuroscience for animal welfare. The following mouse lines were used: a parvalbumin-Cre recombinase line (Pvalb-Cre; 008069, Jackson Laboratory; Hippenmeyer et al., 2005), a GAD67-GFP transgenic line (G42; 007677, Jackson Laboratory; Chattopadhyaya et al., 2004), a loxP-STOP-loxP-tdTomato Cre reporter line (Ai9; 007905, Jackson Laboratory; Madisen et al., 2010), and a loxP-STOP-loxPchannelrhodopsin-2-eYFP Cre-dependent line (ChR2-eYFP, Ai32; 012569, Jackson Laboratory; Madisen et al., 2012). Mice were all on mixed backgrounds composed primarily of C57BL/6 and CD-1.

Stereotaxic injections of neuronal tracers and viral vectors. Cortical injections of neuronal tracers were used to retrogradely label ClaC neurons. Briefly, mice of either sex, ranging from postnatal day (P) 20 to P55, were anesthetized with ketamine $(50 \mathrm{mg} / \mathrm{kg})$, dexmedetomidine $(25 \mu \mathrm{g} / \mathrm{kg})$, and the inhalation anesthetic, isoflurane, in oxygen (1-3\%). Animals were placed in a custom-built stereotaxic frame and anesthesia was maintained with isoflurane. After performing a small craniotomy, a total of $0.8-1.5 \mu \mathrm{l}$ of a suspension of tracer was injected in 9-16 sites in the visual, auditory, and/or somatomotor cortex through a glass pipette (20-30 $\mu \mathrm{m}$ inner tip diameter) using stereotaxic coordinates derived from a mouse brain atlas (Franklin and Paxinos, 2007) and empirically confirmed. Four fluorescent neuronal tracers were used interchangeably with similar results: green and red Retrobeads (Lumafluor) and green and red Alexa-conjugated cholera toxin B (Alexa-488 and Alexa-555 $\mathrm{CTB}$, Invitrogen). A similar approach was used to express the fusion proteins channelrhodopsin-2-eYFP (ChR2-eYFP) and ChR2-mCherry in corticoclaustral axons. Briefly, adeno-associated viral vectors were injected into the cortex [AAV1-CaMKII $\alpha$-hChR2(H134R)-eYFP, AAV1-CaMKII $\alpha$-hChR2(H134R)-mCherry, and AAV-DJ-CaMKII $\alpha$ hChR2(H134R)-eYFP; the National Institute of Drug Abuse Optogenetics and Transgenic Technology Core and the Stanford University Neuroscience Gene Vector and Virus Core]. Because no significant differences in the responses were identified among the viral constructs, the results were pooled for analysis. Buprenorphine $(0.05 \mathrm{mg} / \mathrm{kg})$ was administered to all animals postoperatively. We waited $\geq 48 \mathrm{~h}$ to visualize retrogradely labeled $\mathrm{ClaC}$ neurons and $\geq 2$ weeks for $\mathrm{ChR} 2$ expression before cutting brain slices. We did not observe any ChR2-expressing $\mathrm{ClaC}$ neurons retrogradely transduced through their axon terminals in the cortex in any slice.

Anatomical and immunohistochemical analysis. To analyze the location of the retrogradely labeled neurons and axonal projections, mice were deeply anesthetized with isoflurane and then decapitated. The brain was removed and placed in a solution of $4 \%$ paraformaldehyde (PFA; Electron Microscopy Sciences) in $0.01 \mathrm{~m}$ PBS for $>2 \mathrm{~h}$. Coronal sections (100-300 $\mu \mathrm{m}$ thick) were prepared on a vibratome (VT-1000s, Leica), then mounted using Vectashield (Vector Laboratories) or Aqua Poly/ Mount (Polysciences) and visualized either on an epifluorescence microscope (Axiophot, Zeiss) using $2.5 \times(0.075$ numerical aperture $), 5 \times(0.15$ numerical aperture $), 10 \times(0.25$ numerical aperture $)$, or $20 \times(0.5 \mathrm{nu}-$ merical aperture) objectives or on a confocal microscope (LSM 510, Zeiss ) using $5 \times(0.15$ numerical aperture $), 10 \times(0.3$ numerical aperture), or $20 \times(0.8$ numerical aperture) objectives. A subset of slices was processed for parvalbumin immunohistochemistry. Briefly, fixed slices were washed in $0.01 \mathrm{~m}$ PBS, then incubated for $1 \mathrm{~h}$ in PBS with $0.25 \%$ Triton X-100 and 5\% normal goat serum. The slices were then incubated at $4^{\circ} \mathrm{C}$ overnight in the same solution with primary antibodies against parvalbumin (rabbit anti-parvalbumin, 1:1000; PV25, Swant). Following three 10 min rinses in PBS, the slices were incubated for $2 \mathrm{~h}$ at room temperature in secondary antibody (Alexa- 488 goat anti-rabbit, 1:300; Invitrogen). The slices were then mounted and visualized as described above.

Slice preparation. Acute coronal brain slices (300 $\mu \mathrm{m}$ thick) were generated for in vitro recording and optical stimulation largely as previously described (Brown and Hestrin, 2009a; Kim et al., 2014). After anesthetizing the mice (P24-P105) with isoflurane, brains were isolated in an 
ice-cold sucrose solution composed of the following (in mM): $76 \mathrm{NaCl}, 25$ $\mathrm{NaHCO}_{3}, 25$ glucose, 75 sucrose, $2.5 \mathrm{KCl}, 1.25 \mathrm{NaH}_{2} \mathrm{PO}_{4}, 0.5 \mathrm{CaCl}_{2}, 7$ $\mathrm{MgSO}_{4}, \mathrm{pH} 7.3,315 \mathrm{mOsm}$. Coronal slices were sectioned on a vibratome (VT-1200s, Leica) in the same ice-cold sucrose solution, and then incubated in warm $\left(32-35^{\circ} \mathrm{C}\right)$ sucrose solution for $30 \mathrm{~min}$. Slices were then transferred to warm $\left(32-35^{\circ} \mathrm{C}\right)$ artificial CSF (ACSF) composed of the following (in mM): $125 \mathrm{NaCl}, 26 \mathrm{NaHCO}_{3}, 2.5 \mathrm{KCl}, 1.25$ $\mathrm{NaH}_{2} \mathrm{PO}_{4}, 1 \mathrm{MgSO}_{4}-7 \mathrm{H}_{2} \mathrm{O}, 20$ glucose, $2 \mathrm{CaCl}_{2}-2 \mathrm{H}_{2} \mathrm{O}, 0.4$ ascorbic acid, 2 pyruvic acid, 4 L-lactic acid, $\mathrm{pH} 7.3,315 \mathrm{mOsm}$. The solution was then allowed to cool to room temperature. This same ACSF solution was also used for all subsequent recordings. All solutions were continuously bubbled with $95 \% \mathrm{O}_{2} / 5 \% \mathrm{CO}_{2}$.

Cell identification and electrophysiological recordings. For recordings, slices were transferred to a submersion chamber on an upright microscope (Zeiss AxioExaminer; $40 \times$ objective, 1.0 numerical aperture) and were continuously superfused $(2-4 \mathrm{ml} / \mathrm{min})$ with warm $\left(32-34^{\circ} \mathrm{C}\right)$, oxygenated ACSF. The claustrum was identified either by the location of retrogradely labeled ClaC neurons or by the dense PV fiber plexus in G42 or PV-Cre;tdTomato mice. Neurons were visualized with a digital camera (Sensicam QE, Cooke) using transmitted light with infrared differential interference contrast optics and epifluorescence. Neurons were targeted within the labeled region using glass recording electrodes (2-4 $\mathrm{M} \Omega$ ) filled with one of three internal solutions. For experiments related to synaptic connections between PV neurons (see Fig. $3 D-G$ ), the pipette was filled with a solution containing the following (in $\mathrm{mM}$ ): $36.4 \mathrm{KCl}, 96.4$ $\mathrm{KMeSO}_{3}$, 9.1 HEPES, 0.18 EGTA, 4 MgATP, 0.3 NaGTP, 20 phosphocreatine(Na), pH 7.3, $295 \mathrm{mOsm}$; except for two PV-PV pairs that were recorded with a solution containing the following (in $\mathrm{mM}$ ): $2.7 \mathrm{KCl}, 120$ $\mathrm{KMeSO}_{3}$, 9 HEPES, 0.18 EGTA, 4 MgATP, 0.3 NaGTP, 20 phosphocreatine $(\mathrm{Na})$, pH 7.3, $295 \mathrm{mOsm}$. For voltage-clamp recordings (see Fig. $7 \mathrm{D}, E$ ), the pipette was filled a solution containing the following (in $\mathrm{mm}$ ): $3 \mathrm{CsCl}, 119.25 \mathrm{CsMeSO}_{3}$, 10 HEPES, 0.2 EGTA, 4 MgATP, 0.3 NaGTP, 20 phosphocreatine $(\mathrm{Na}), \mathrm{pH}$ 7.3, $295 \mathrm{mOsm}$. For all other recordings, the pipette was filled with a solution containing the following (in $\mathrm{mM}$ ): $2.7 \mathrm{KCl}, 120 \mathrm{KMeSO}_{3}$, 9 HEPES, 0.18 EGTA, 4 MgATP, $0.3 \mathrm{NaGTP}, 20$ phosphocreatine $(\mathrm{Na}), \mathrm{pH} 7.3,295 \mathrm{mOsm}$.

$\mathrm{ClaC}$ neurons were retrogradely labeled with a fluorescent tracer for targeted recordings. PV interneurons were targeted for recording in PVCre;tdTomato or G42 mice. Whole-cell patch-clamp recordings were obtained simultaneously from pairs of claustral neurons using a Multiclamp 700B patch amplifier (Molecular Devices) in voltage-clamp and current-clamp modes controlled by custom-written routines in Igor Pro (WaveMetrics). All signals were low-pass filtered at $10 \mathrm{kHz}$ and digitized at $20-100 \mathrm{kHz}$ (ITC-18, Instrutech). Data acquisition and analysis were performed using custom software written in Igor Pro (WaveMetrics). The access resistance averaged $13.4 \pm 6.1 \mathrm{SD} \mathrm{M} \Omega$ for ClaC neurons $(n=$ $200)$ and $11.5 \pm 5.9 \mathrm{SD} \mathrm{M} \Omega$ for PV neurons $(n=135)$ and was not compensated. Results were not corrected for the liquid junction potential. All chemicals were purchased from Tocris Bioscience or SigmaAldrich.

Photostimulation of ChR2. ChR2 was photoactivated as previously described (Kim et al., 2014). Briefly, a small circle of blue light (110-315 $\mu \mathrm{m}$ diameter) was focused onto the brain slice using a fiber optic cable (920 $\mu \mathrm{m}$ diameter; Thorlabs) coupled to a blue LED ( $\sim 40 \mathrm{~nm}$; Luminous) focused onto the focal plane of a camera port with a $10 \times 0.3$ numerical aperture lens. Brief light pulses (0.5-3 ms each, 6-600 mW/ $\mathrm{mm}^{2}$ ) were delivered through the $40 \times$ objective centered over the recorded neurons in the claustrum and synaptic responses were recorded in claustral neurons ipsilateral to the injection site in current-clamp or voltage-clamp mode. Mice in which no response was recorded in any tested claustral neuron were eliminated from the analysis $(n=4)$. ClaC neurons rarely fired action potentials under our stimulation conditions. However, one $\mathrm{ClaC}$ neuron that predominantly fired action potentials in response to cortical inputs during the recordings was also eliminated from the analysis.

Morphological analysis. To assess the morphology of claustral neurons, $0.25 \% \mathrm{w} / \mathrm{v}$ biocytin was included in the pipette recording solution of at least one of the two pipettes. Following the electrophysiological experiments, slices were fixed in 4\% PFA in $0.01 \mathrm{~m}$ PBS. To visualize biocytin- filled cells, we processed the slices in two ways. First, after rinses in $0.01 \mathrm{M}$ PBS, slices were incubated for $1 \mathrm{~h}$ in PBS with 2\% Triton X-100 followed by $16-24 \mathrm{~h}$ at $4^{\circ} \mathrm{C}$ in a solution with Alexa-488-conjugated or Alexa-647conjugated streptavidin (1:200; Invitrogen) and subsequently mounted in Aqua Poly/Mount before being visualized on a confocal microscope (LSM510, Zeiss). Alternatively, 3,3'-diaminobenzidine (DAB) was used to visualize the neurons. Briefly, slices were pretreated with $\mathrm{H}_{2} \mathrm{O}_{2}$ (Sigma-Aldrich), rinsed, and incubated in a solution containing $2 \%$ Triton X-100 (Sigma-Aldrich) in PBS for 1-2 h at room temperature. Slices were then incubated in a standard avidin-biotin solution (Vectastain Elite ABC Kit, Vector Laboratories) and DAB was used to visualize the neurons. Signals were further enhanced by briefly treating the tissue with $\mathrm{OsO}_{4}$ (Electron Microscopy Sciences). The DAB-processed slices were mounted in Mowiol mounting media or Aqua Poly/Mount. Individual neurons were reconstructed in three dimensions using a Neurolucida system (MicroBrightfield) on an Imager.M2 microscope ( $100 \times 1.4 \mathrm{nu}-$ merical aperture, $40 \times 1.3$ numerical aperture, and $25 \times 0.8$ numerical aperture oil-immersion objectives; Zeiss). No correction was made for tissue shrinkage.

Data analysis. All data analysis was performed in Igor Pro, Excel (Microsoft), and Vassar Stats (http://vassarstats.net/tab2x2.html). Recordings with a resting membrane potential $>-60 \mathrm{mV}$ were eliminated from further analysis. To assess the spiking behavior of the cell, 1-s-long depolarizing current steps were injected into the cells. The properties of action potentials were analyzed using traces in which only single action potentials were elicited. For unitary connections, two presynaptic action potentials at $20 \mathrm{~Hz}$ were generated by two $3-5 \mathrm{~ms}$ injections of current. The postsynaptic potentials of unitary connections were aligned to the first presynaptic spike before averaging. For optogenetic experiments, brief light flashes $(0.5-3 \mathrm{~ms}$ each) were delivered at $10 \mathrm{~Hz}$. Synaptic connectivity was typically assessed by averaging $10-100$ individual traces separated by $10 \mathrm{~s}$. In Figures $3 B, E$, and $4 B, C$, the aligned and averaged postsynaptic potential is shown along with a single pair of presynaptic spikes. The paired-pulse ratio (PPR) was calculated by taking the ratio of the amplitude of the second response over the amplitude of the first response. For $\mathrm{PV} \rightarrow \mathrm{PV}$ connections, the PPR was calculated only for those pairs that were not electrically connected. The PPR could not be calculated for two $\mathrm{PV} \rightarrow \mathrm{ClaC}$ connections due to the small amplitude of the responses. To assess electrical connections, a $1 \mathrm{~s}$ hyperpolarizing current pulse was used to calculate the coupling coefficient $\left(V_{2} / V_{1}\right)$, the ratio of the amplitude of the voltage change in the noninjected cell $\left(V_{2}\right)$ and the amplitude of the voltage change in the injected cell $\left(V_{1}\right)$. When comparing corticoclaustral input to $\mathrm{ClaC}$ and $\mathrm{PV}$ neurons, neither cell responded to cortical input in six pairs and were not included in the analysis (see Fig. 7C). When comparing the latency of inward (excitatory) and outward (inhibitory) currents evoked by corticoclaustral input, a small inward current preceded the outward current at $0 \mathrm{mV}$ in five cells, making it difficult to calculate the latency of inhibition, and these were not included in the summary data (see Fig. 7E). For those pairs for which the intersomatic distance was measured, the average distance between the two cell bodies was $101 \mu \mathrm{m}$ (range: 29 to $203 \mu \mathrm{m}, n=107$ pairs). There was no statistically significant difference in the distance between connected and unconnected pairs for any of the connection types tested. Responses following optogenetic activation were not aligned before averaging. Stimulation artifacts were removed from the traces in Figure 6C,E. Data are presented as the mean \pm SEM unless otherwise noted.

\section{Results}

\section{Identification of the claustrum}

To identify the claustrum in the mouse, we injected fluorescent retrograde neuronal tracers into the visual, somatosensory, auditory, or motor cortex to label ClaC neurons. Following such injections, we found dense labeling of the claustrum ipsilateral to the injection site (Fig. $1 A, B$ ). Previous studies in several model organisms have shown that the claustrum contains a dense plexus of parvalbumin-immunoreactive processes (Druga et al., 1993; Real et al., 2003; 
Hinova-Palova et al., 2007, 2014; Rahman and Baizer, 2007). We confirmed that the retrogradely labeled ClaC neurons and this $\mathrm{PV}$-positive region underlying the cortex were colocalized (Fig. $1 C-F)$. The location of retrogradely labeled $\mathrm{ClaC}$ neurons or genetically identified PV neurons allowed us to target cell types within the claustrum for whole-cell patch-clamp recordings in acute brain slices.

\section{Cell types within the claustrum}

Because the patterns and properties of synaptic connectivity depend on the identity of the presynaptic and postsynaptic cell types, identifying the cell types that make up a neural circuit represents an essential step in deciphering its functional organization (Hestrin and Galarreta, 2005; Brown and Hestrin, 2009b; KrookMagnuson et al., 2012). The claustrum primarily contains large, spiny neurons that likely represent excitatory $\mathrm{ClaC}$ neurons (Brand, 1981; LeVay and Sherk, 1981; Braak and Braak, 1982; Druga, 2014). In addition, the claustrum's dense plexus of PV processes likely stems from local aspiny interneurons (Brand, 1981; LeVay and Sherk, 1981; Braak and Braak, 1982; Druga et al., 1993; Kowiański et al., 2001; Real et al., 2003; Rahman and Baizer, 2007). Using a combination of retrograde labeling of $\mathrm{ClaC}$ neurons and genetic identification of PV neurons in the claustrum, we analyzed the morphological and electrophysiological profiles of these two types of claustral neurons in acute brain slices of the mouse.

ClaC neurons typically had thick dendrites emanating from the cell body, and their dendrites were densely spiny (Fig. 2A-C). The axons typically originated either from the cell body or from a large primary dendrite. In some filled neurons in which the axon was not cut within the claustrum, we could clearly identify a long axonal process traveling through the white matter toward the cortex (Fig. 2D). Even in these cases, however, filled ClaC neurons had relatively sparse axonal arbors within the claustrum itself. During depolarizing current steps, these neurons typically showed some degree of spike frequency adaptation, although some cells were regular spiking or even exhibited a doublet at the onset of the depolarization (Fig. 2E). During long step depolarizations, neurons often showed brief pauses in spiking (Fig. $2 E$, right). Additional electrophysiological properties are summarized in Table 1.

To target PV neurons in the claustrum for electrophysiological recording, we used two lines of mice in which a fluorescent protein is selectively expressed in PV cells: the G42 line or a PVCre line crossed with a Cre-dependent reporter line (Fig. $2 F$ ). In contrast to $\mathrm{ClaC}$ neurons, $\mathrm{PV}$ interneurons had smooth dendrites, and each cell formed a dense plexus of axonal boutons within the claustrum that was strikingly different from the axonal pattern seen with ClaC neurons (Fig. $2 G-I$ ). In a few cases, axonal boutons could clearly be seen surrounding a cell body of another claustral cell visualized with differential interference contrast microscopy. Although some cells had processes that extended into the overlying cortex, we did not identify any instances of an axonal process coursing in the white matter toward the cortex as seen with $\mathrm{ClaC}$ neurons (Fig. 2D). Rather, the processes of PV interneurons seemed largely confined to the claustrum (Fig. $2 H$ ).

The electrophysiological properties of PV interneurons were also quite different from those of ClaC principal neurons (Fig. 2J; Table 1). These PV cells had a significantly lower input resistance and a higher resting membrane potential than ClaC neurons ( $\mathrm{Ta}-$ ble 1). PV neurons were fast-spiking cells, and their action potential shape was significantly different from that of ClaC cells (Table 1). They also exhibited other features typical of fast-spiking cells, including pauses in their firing and oscillations in the membrane voltage (Fig. 2J). In contrast to previous work that found no correlation between the spiking patterns and dendritic morphologies of randomly targeted claustral neurons (Shibuya and Yamamoto, 1998), these data confirm that retrogradely labeled $\mathrm{ClaC}$ neurons and genetically identified PV interneurons in the claustrum are morphologically and electrophysiologically distinct.

\section{$\mathrm{ClaC}$ neurons within the claustrum are rarely interconnected} Excitatory recurrent connections among $\mathrm{ClaC}$ neurons may allow them to integrate and amplify their synaptic input (Crick and Koch, 2005; Smythies et al., 2012, 2014b). If ClaC neurons form frequent synaptic connections with each other, this circuit organization could increase the gain and prolong the response to corticoclaustral signals (L. Y. Li et al., 2013, Y. T. Li et al., 2013; Lien and Scanziani, 2013). Alternatively, a sparsely connected network of $\mathrm{ClaC}$ neurons would argue against broad excitatory integration within this structure. Although anatomical experiments indicate that spiny projection neurons as well as aspiny 

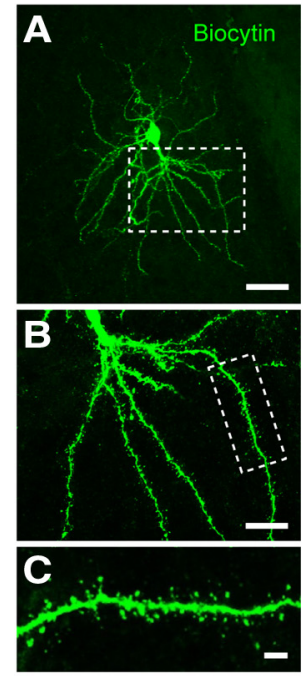

E

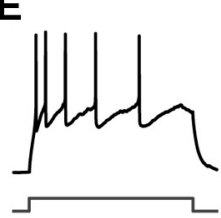

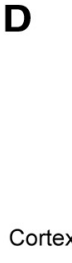

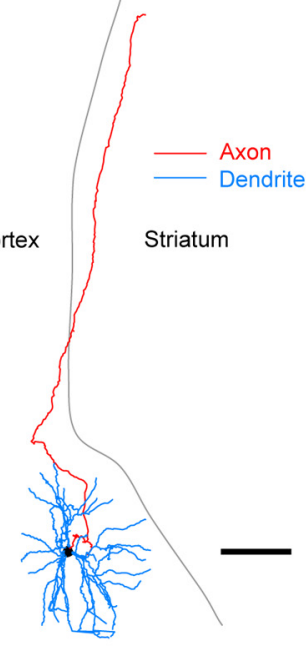

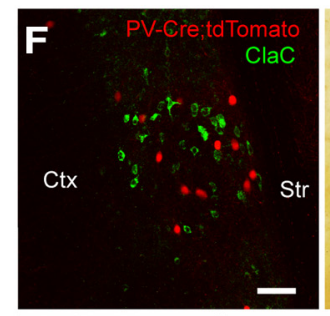
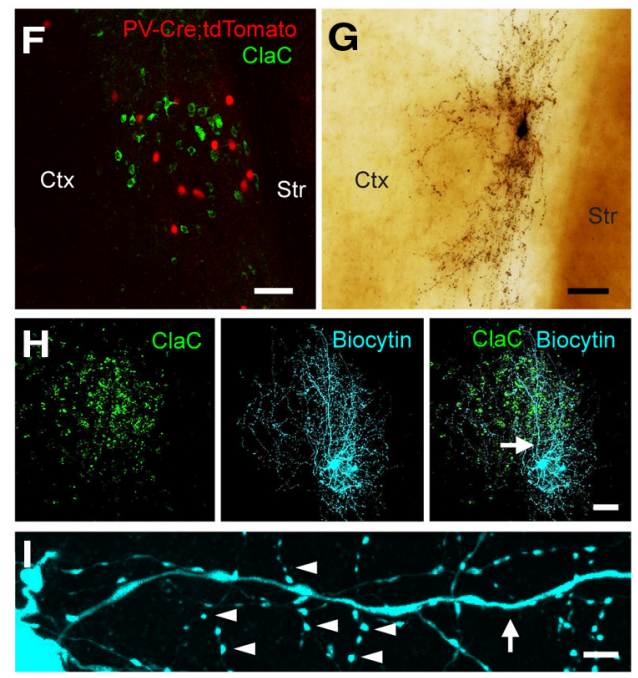

$\mathbf{J}$
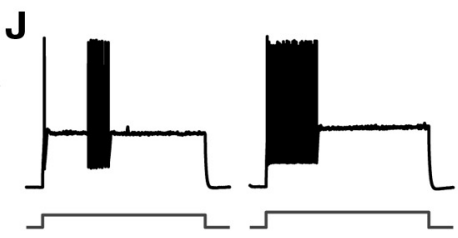

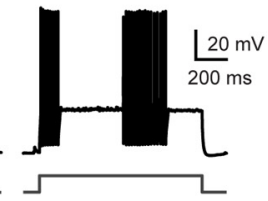

Figure 2. Morphological and electrophysiological properties of retrogradely labeled ClaC neurons and PV claustral neurons. A, Low-magnification image of a retrogradely labeled ClaC neuron filled with biocytin (green). $\boldsymbol{B}$, Higher-magnification view of the robust proximal dendrites and further dendritic branching of this cell in the region outlined by the white box in $\boldsymbol{A}$. $\boldsymbol{C}$, Highermagnification view of the dendrite and dendritic spines of the region outlined by the white box in $\boldsymbol{B}$. $\boldsymbol{D}$, Morphological reconstruction of a second biocytin-filled $\mathrm{Cla} C$ neuron. Dendrites are shown in blue, axons in red. Note the long axonal branch coursing through the white matter toward the cortex. $E$, Current-clamp recordings of the responses of three different ClaC neurons during injections of a 1 s depolarizing current pulse (left and middle, $100 \mathrm{pA}$; right, $200 \mathrm{pA}$ ). $\boldsymbol{F}$, Image of retrogradely labeled ClaC neurons (green) and PV neurons (red) in a coronal section from a PV-Cre;tdTomato mouse. G, Image of a PV neuron filled with biocytin. $\boldsymbol{H}$, Image of retrogradely labeled ClaC neurons (left, green) and a second biocytin-filled PV neuron (middle, blue). The superimposed images show the correspondence between the PV neuron's axonal and dendritic processes and the region containing retrogradely labeled ClaC cells in the claustrum (right). The arrow indicates the location of the dendrite shown at higher magnification in $\boldsymbol{I}$. $\boldsymbol{I}$, A higher-magnification view of the PV neuron in $\boldsymbol{H}$ showing a smooth dendrite (arrow) and examples of the neuron's many axonal boutons (arrowheads).J, Current-clamp recordings of responses from three different claustral PV neurons during injections of $1 \mathrm{~s}$ depolarizing current pulses (left, $300 \mathrm{pA}$; middle, $370 \mathrm{pA}$; right, $400 \mathrm{pA}$ ). Ctx, Cortex; Str, striatum. Scale bars: $\boldsymbol{A}, 50 \mu \mathrm{m} ; \boldsymbol{B}, 20 \mu \mathrm{m} ; \boldsymbol{C}, 5 \mu \mathrm{m} ; \boldsymbol{D}, 100 \mu \mathrm{m} ; \boldsymbol{F}-\boldsymbol{H}, 50 \mu \mathrm{m} ; \boldsymbol{I}, 5 \mu \mathrm{m}$.

Table 1. Intrinsic properties of $\mathrm{ClaC}$ and $\mathrm{PV}$ neurons in the claustrum

\begin{tabular}{lccl}
\hline Properties & \multicolumn{1}{l}{ ClaC neurons } & PV interneurons & $p$ value \\
\hline Input resistance $(\mathrm{M} \Omega)$ & $307.9 \pm 9.4(247)$ & $104.5 \pm 4.9(111)$ & $p<0.0001$ \\
Resting membrane & $-78.7 \pm 0.5(247)$ & $-75.6 \pm 0.6(111)$ & $p=0.0003$ \\
$\quad$ potential (mV) & & & \\
Spike rate of rise $(\mathrm{V} / \mathrm{s})$ & $211.9 \pm 6.5(99)$ & $325.6 \pm 11.4(49)$ & $p<0.0001$ \\
Spike rate of fall (V/s) & $-66.2 \pm 1.6(99)$ & $-230.8 \pm 10.5(49)$ & $p<0.0001$ \\
Spike threshold (mV) & $-35.8 \pm 0.6(99)$ & $-38.4 \pm 0.8(49)$ & $p=0.0091$ \\
Spike half-width (ms) & $1.00 \pm 0.02(99)$ & $0.35 \pm 0.01(49)$ & $p<0.0001$ \\
\hline
\end{tabular}

All data are presented as mean \pm SEM with the numbers of tested neurons in parentheses. An unpaired $t$ test was used to compare the two cell types.

interneurons form synapses within the claustrum, how neuronal circuits within the claustrum are organized remains an open question (Juraniec et al., 1971; LeVay and Sherk, 1981; HinovaPalova et al., 2007).

We first tested whether we could identify unitary synaptic connections among ClaC neurons. We targeted pairs of retrogradely labeled $\mathrm{ClaC}$ neurons for simultaneous patch-clamp recordings (Fig. $3 A$ ). We found unitary excitatory synaptic connections among ClaC neurons (Fig. 3B; PPR: 0.7 and 1.2, $n=2$ connections). However, the probability of connection was quite low, indicating that unitary connections among $\mathrm{ClaC}$ neurons are rare (Fig. $3 C$ ). We also tested whether $\mathrm{ClaC}$ neurons were interconnected via electrical synapses. We did not identify any electrical connections among ClaC neurons $(n=0$ of 25 tested pairs). The distance between the two somas for the two connected pairs was 80 and $128 \mu \mathrm{m}$. The average intersomal distance for the unconnected pairs that we measured was $96 \mu \mathrm{m}$ (range: 29 to 175 $\mu \mathrm{m}, n=39$ pairs) and included 14 connections tested in the $\sim 30$ to $\sim 60 \mu \mathrm{m}$ range. Together, our results suggest that it is unlikely that local synaptic connections among ClaC neurons broadly integrate activity within the claustrum.

\section{PV interneurons are highly interconnected within the claustrum}

Because the claustrum is notable for its dense plexus of PV processes, we next asked whether PV neurons are interconnected within the claustrum. Highly interconnected networks of PV interneurons could serve to generate rhythmic or synchronous activity within the claustrum (Galarreta and Hestrin, 1999, 2001; Gibson et al., 1999). To determine the synaptic organization of these cells, we recorded from pairs of PV neurons identified in brain slices from G42 or PV-Cre mice crossed with a Cre-dependent reporter line (Fig. 3D). A high chloride $(36.4 \mathrm{~mm}$ $\mathrm{KCl}$ ) internal solution was used to increase the driving force for chloride and enhance our ability to detect inhibitory synaptic connections. We detected unitary chemical connections as well as electrical synaptic connections among claustral PV neurons (Fig. $3 E, F)$. The chemical connections were inhibitory when recorded with a low-chloride $(2.7 \mathrm{mM} \mathrm{KCl})$ internal solution, confirming that PV interneurons in the claustrum are inhibitory (data not shown). The connection probability for both chemical and electrical synapses between PV interneurons was high (Fig. $3 G$ ). The chemical connections between PV interneurons were depressing with a PPR of $0.66 \pm 0.03$. The coupling coefficient among elec- 
trically connected PV neurons ranged from 2.4 to $10.9 \%$ (mean: $5.7 \pm 0.7 \%$ ). The average distance between the somas that we measured was $90 \mu \mathrm{m}$ for connected pairs (range: 54 to $154 \mu \mathrm{m}, n=8$ pairs) and $100 \mu \mathrm{m}$ for unconnected pairs (57 and $142 \mu \mathrm{m}, n=2$ pairs). These data indicate that this sparse population of PV interneurons is highly interconnected with both chemical and electrical synaptic connections.

PV interneurons and claustral principal cells are highly interconnected

If ClaC neurons and PV neurons are synaptically connected, the highly interconnected network of PV neurons within the claustrum could serve to detect and amplify correlated inputs from $\mathrm{ClaC}$ neurons and coordinate the activity of claustral projection neurons (Galarreta and Hestrin, 2001; Cardin et al., 2009; Sohal et al., 2009). Electron microscopy studies of the claustrum hint at connections between spiny and aspiny neurons (LeVay and Sherk, 1981; Hinova-Palova et al., 2007). We next asked whether the principal cells of the claustrum, ClaC neurons, and claustral PV neurons are interconnected. We recorded simultaneously from pairs of neurons composed of one retrogradely labeled $\mathrm{ClaC}$ cell and one claustral PV neuron identified in G42 or PV-Cre; tdTomato mice (Fig. 4A). We identified excitatory unitary connections from $\mathrm{ClaC}$ neurons onto PV neurons, as well as inhibitory unitary connections from claustral PV neurons onto ClaC cells (Fig. $4 B, C)$. Indeed, these two cell types were highly interconnected in both directions (Fig. 4D). For $\mathrm{ClaC} \rightarrow \mathrm{PV}$ and $\mathrm{PV} \rightarrow \mathrm{ClaC}$ connections, the average intersomal distance that we measured for connected and unconnected pairs was not significantly different $(\mathrm{ClaC} \rightarrow \mathrm{PV}$ : connected average: $100 \mu \mathrm{m}$, range: 47 to $203 \mu \mathrm{m}, n=11$ pairs; unconnected average: $110 \mu \mathrm{m}$, range: 67 to $190 \mu \mathrm{m}, n=17$ pairs; $\mathrm{PV} \rightarrow \mathrm{ClaC}$ : connected average: $125 \mu \mathrm{m}$, range: 72 to $203 \mu \mathrm{m}, n=6$ pairs; unconnected average: $101 \mu \mathrm{m}$, range: 47 to 190 $\mu \mathrm{m}, n=22$ pairs). Five of the pairs we tested were bidirectionally connected, suggesting that PV cells may contribute to feedback inhibition in the claustrum $(\mathrm{Hu}$ et al., 2014). The PPR was depressing for both $\mathrm{ClaC} \rightarrow \mathrm{PV}$ and $\mathrm{PV} \rightarrow \mathrm{ClaC}$ connections $(\mathrm{ClaC} \rightarrow \mathrm{PV}: 0.70 \pm 0.06, n=13$ pairs; $\mathrm{PV} \rightarrow$ ClaC: $0.59 \pm 0.04, n=9$ pairs). These results suggest that the network of PV inhibitory neurons within the claustrum may strongly influence the activity of $\mathrm{ClaC}$ neurons.
A

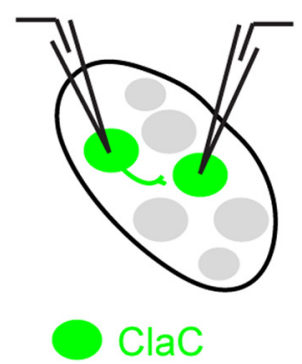

D

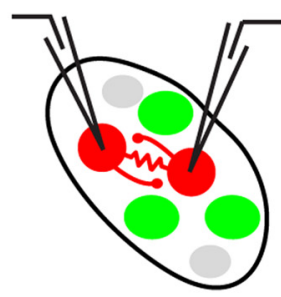

$\mathrm{PV}$
$\mathrm{ClaC}$
B

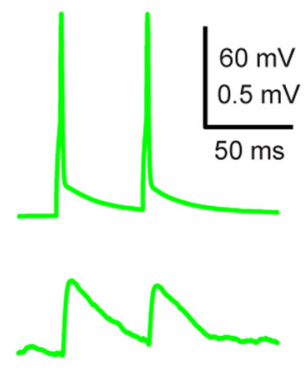

C

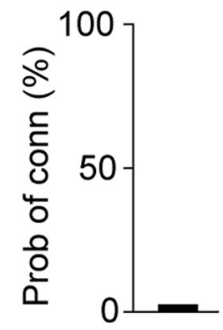

$\mathbf{E}$

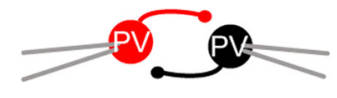

$\mathbf{F}$
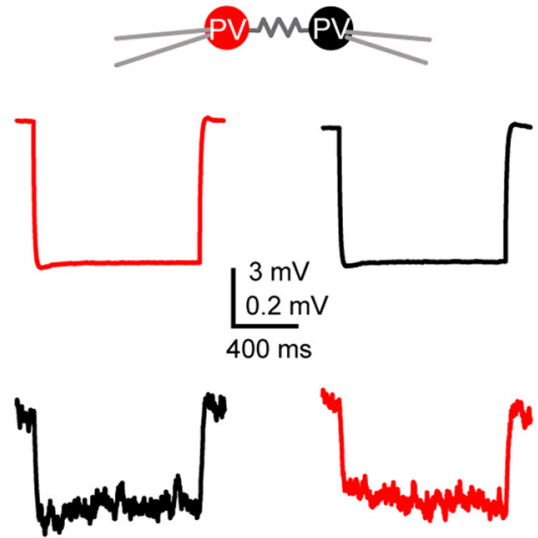

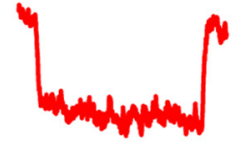

G

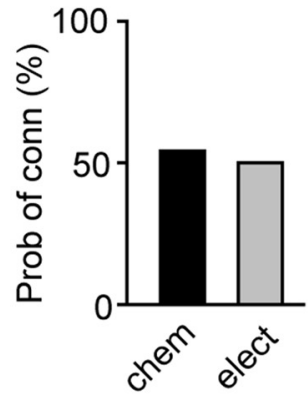

Figure 3. ClaC neurons are sparsely interconnected within the claustrum, whereas PV claustral neurons form frequent chemical and electrical synaptic connections. $\boldsymbol{A}$, Schematic of a paired recording from two retrogradely labeled $\mathrm{ClaC}$ neurons. $\boldsymbol{B}$, Average synaptic response recorded in a $\mathrm{ClaC}$ neuron (bottom trace) following action potentials induced in a presynaptic ClaC cell (top trace) during simultaneous recordings from a pair of monosynaptically connected ClaC neurons. C, The frequency of identified connections among ClaC connections tested (2 connections identified in 86 connections tested). D, Schematic of a paired recording from two claustral PV neurons. $\boldsymbol{E}$, Bidirectional chemical synaptic connections between two simultaneously recorded PV neurons in the claustrum. Action potentials in each presynaptic PV neuron (top traces) evoked synaptic responses in the simultaneously recorded postsynaptic PV neuron (bottom traces). The postsynaptic potentials are depolarizing because the recordings were performed with a high-chloride internal solution. This pair of PV neurons was not electrically coupled. $\boldsymbol{F}$, Electrical synaptic connections between two PV claustral neurons. A hyperpolarizing current step ( $-100 \mathrm{pA}$, top traces) evoked a corresponding response in the electrically connected partner (bottom traces) during simultaneous recordings from an electrically connected pair of PV neurons. G, Summary data showing the probability of connection for chemical ( $n=13$ of 24 tested connections) and electrical synaptic connections ( $n=6$ of 12 tested connections). The configurations for the identified connections were as follows: PV $\rightarrow$ PV: one pair; PV↔PV: two

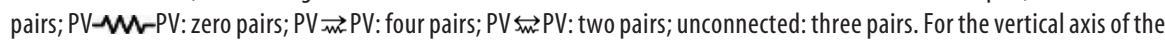
calibration bars in $\boldsymbol{B}, \boldsymbol{E}$, and $\boldsymbol{F}$, the top value is for the presynaptic cell and the bottom value is for the postsynaptic response. 
A

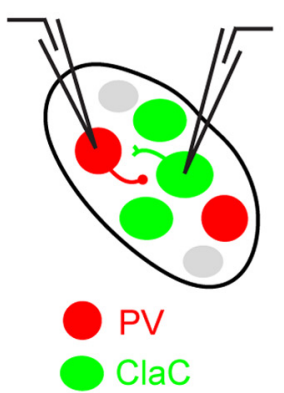

B

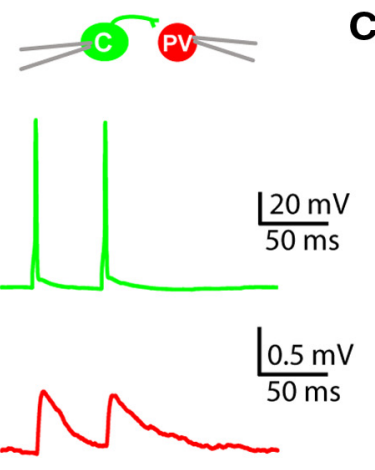

C
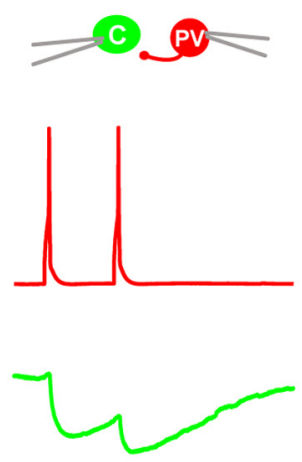

Figure 4. $\quad \mathrm{ClaC}$ neurons and PV claustral neurons form frequent unitary synaptic connections within the claustrum. $\boldsymbol{A}$, Schematic of a paired recording from a retrogradely labeled $C$ laC neuron and a PV neuron. $\boldsymbol{B}$, A unitary excitatory synaptic connection between a presynaptic (laC neuron (green) and a postsynaptic PV neuron (red). $\boldsymbol{C}$, A unitary inhibitory synaptic connection between a presynaptic PV neuron (red) and a postsynaptic ClaC neuron (green). This recording is from a different pair than that shown in $\boldsymbol{B}$. $\boldsymbol{D}$, Summary data showing the probability of connection for $\mathrm{ClaC} \rightarrow \mathrm{PV}$ and PV $\rightarrow \mathrm{ClaC}$ connections (ClaC $\rightarrow$ PV: $n=13$ of 38 tested connections; PV $\rightarrow$ ClaC: $n=11$ of 38 tested connections; ClaC $\rightarrow$ PV: 8 pairs; PV $\rightarrow$ ClaC: 6 pairs; ClaC $\leftrightarrow$ PV: 5 pairs; unconnected: 19 pairs).

It is interesting to note that the identity of the postsynaptic neuron plays an important role in determining the connections of $\mathrm{ClaC}$ neurons. Although PV neurons are vastly outnumbered by $\mathrm{ClaC}$ neurons in the claustrum, the probability of detecting a $\mathrm{ClaC} \rightarrow \mathrm{PV}$ connection was $34 \%$, while the probability of identifying a ClaC $\rightarrow$ ClaC connection was only $2.3 \%$ in our study ( $p=0.0000026$, Fisher exact test). Thus, a ClaC neuron is $\sim 15$-fold more likely to synapse onto a PV neuron than onto another ClaC neuron. The difference in the probability of connection for $\mathrm{PV} \rightarrow \mathrm{PV}$ and $\mathrm{PV} \rightarrow \mathrm{ClaC}$ connections was not statistically significantly different $(p=0.063$, Fisher exact test).

\section{Corticoclaustral axons synapse onto both ClaC neurons and PV neurons}

How cortical input stimulates $\mathrm{ClaC}$ neurons and PV neurons in the claustrum has important implications for the function of claustral circuits. Corticoclaustral neurons are found in the infragranular layers of the cortex and represent a separate population from the more-studied L6 corticothalamic neurons (Olson and Graybiel, 1980; Sherk and LeVay, 1981a; Katz, 1987; Smith and Alloway, 2010). Degeneration studies combined with electron microscopy have demonstrated that corticoclaustral afferents synapse onto putative ClaC cells (Juraniec et al., 1971; LeVay and Sherk, 1981), suggesting that there exists a monosynaptic loop from corticoclaustral neurons onto $\mathrm{ClaC}$ neurons. In addition, a small number of synapses were identified that targeted the beaded dendrites of aspiny neurons (Juraniec et al., 1971; LeVay and Sherk, 1981; Hinova-Palova et al., 1988). These studies suggest that the large majority of the cortical input to the claustrum targets $\mathrm{ClaC}$ cells, but the functional impact of this synaptic organization is not clear. If cortical input drives primarily $\mathrm{ClaC}$ neurons and not PV neurons, it would suggest that cortical activation of $\mathrm{ClaC}$ neurons would then drive PV neurons, which in turn would generate feedback inhibition in ClaC neurons. Alternatively, if corticoclaustral input drives inhibitory neurons strongly, as seen with thalamocortical or corticothalamic inputs, PV neurons could also provide strong feedforward inhibition to ClaC neurons during cortical activity.

To distinguish between these possibilities, we first asked whether we could identify monosynaptic connections from corticoclaustral neurons to $\mathrm{ClaC}$ neurons. To address this question, we next expressed the light-gated cation channel ChR2 in corticoclaustral afferents (Fig. 5A). We stereotaxically injected AAV-
ChR2 into visual or auditory cortex to transduce corticoclaustral neurons while also injecting a fluorescent retrograde tracer to label ClaC neurons. We then identified regions within the claustrum in which both retrogradely labeled ClaC neurons and ChR2-expressing corticoclaustral axons were located. Following optogenetic stimulation of corticoclaustral axons in the claustrum, we identified short-latency postsynaptic potentials (PSPs) in $\mathrm{ClaC}$ neurons (Fig. 5B). Of the ClaC neurons tested, 73\% responded with short-latency PSPs ( $n=51$ of 70 cells tested). We did not detect a response to optogenetic stimulation of corticoclaustral axons in the remaining cells. The evoked responses were blocked by bath application of glutamate receptor antagonists, indicating that these excitatory responses were mediated by glutamate [control: $136.9 \pm 19.1 \mathrm{pA}$; (RS)-3-(2-carboxypiperazin4-yl)-propyl-1-phosphonic acid (CPP) + NBQX: $4.1 \pm 1.5 \mathrm{pA}$, $n=3$ cells]. On average, these connections were depressing (PPR: $0.63 \pm 0.04, n=51$ cells). However, these results must be interpreted with caution as these ChR2-based methods may lead to an overestimation of synaptic depression (Jackman et al., 2014).

To test whether these responses were generated by monosynaptic connections from cortical afferents onto ClaC neurons, we first confirmed that the responses were mediated by action potentials. Bath application of the sodium channel blocker tetrodotoxin (TTX) eliminated the optogenetic responses, indicating that the postsynaptic responses were action potential dependent (Fig. 5C,D). To test whether these responses represented monosynaptic input, we first blocked action potentialdependent responses with bath application of TTX. We then bath applied the potassium channel blocker 4-AP in combination with TTX to enhance ChR2-induced depolarization of the axon terminals of corticoclaustral axons and generate local synaptic release (Petreanu et al., 2009). In the majority of cells tested, a small response was detected in the presence of 4-AP and TTX, indicating that corticoclaustral axons directly synapse onto the recorded ClaC neurons (Fig. $5 E, F$ ). However, the responses were smaller and slower than those seen with action potential-dependent release, suggesting that the dynamics of release are quite different under these conditions. Together, these data demonstrate a functional monosynaptic loop between corticoclaustral afferents and ClaC neurons.

Corticoclaustral input onto PV neurons combined with the high probability of connection between PV neurons and ClaC neurons could represent a circuit mechanism for feedforward inhibition driven by cortical input. Although anatomical studies 
indicate that most cortical input targets ClaC neurons, these studies also suggest that corticoclaustral afferents synapse onto aspiny neurons within the claustrum (Juraniec et al., 1971; LeVay and Sherk, 1981; Hinova-Palova et al., 1988). To test whether corticoclaustral afferents synapse directly onto claustral PV neurons, we again expressed ChR2 in corticoclaustral afferents (Fig. 6A). Following optogenetic stimulation of corticoclaustral axons in the claustrum, we identified short-latency PSPs in PV claustral neurons (Fig. 6B). Of the connections tested, $73 \%$ responded with short-latency PSPs ( $n=38$ of 52 cells tested). We did not detect a response to optogenetic stimulation of corticoclaustral axons in the remaining PV neurons. The PPR of these connections was $0.77 \pm$ 0.06 ( $n=38$ cells), although again this result must be interpreted with caution (Jackman et al., 2014). These responses were action potential dependent as bath application of TTX eliminated the responses (Fig. 6C,D). To test whether corticoclaustral axons formed monosynaptic connections onto PV claustral neurons, we first blocked action potential-dependent postsynaptic responses with bath application of TTX and then applied the potassium channel blocker 4-AP in combination with TTX to measure ChR2induced release. In most cells tested, a small response was detected in the presence of 4-AP and TTX, indicating that corticoclaustral axons directly synapse onto claustral PV neurons (Fig. 6E,F). Together, these data indicate that corticoclaustral cells form monosynaptic connections with both $\mathrm{ClaC}$ cells and PV neurons.

Long-range inputs that target both the inhibitory and excitatory neurons in an interconnected network can evoke potent feedforward inhibition and render the postsynaptic neurons sensitive to the temporal correlations of the input (Bruno, 2011; Hu et al., 2014). To determine whether the claustrum's circuit organization forms a substrate for feedforward inhibition, we next compared the strength of the cortical input onto $\mathrm{ClaC}$ neurons and PV neurons within the claustrum. We recorded from pairs of ClaC and PV cells while optically activating ChR2-expressing cortical afferents (Fig. 7A). This experimental configuration minimized the impact of any variation in levels of ChR2 expression or activation across slices and experimental animals. We found that cortical input to PV cells was, on average, stronger than the input to nearby $\mathrm{ClaC}$ cells (Fig. $7 \mathrm{~B}, \mathrm{C}$ ). We next recorded from ClaC neurons in voltage clamp to isolate the excitatory and inhibitory currents elicited by stimulation of cortical afferents. Excitatory inward currents were measured with $\mathrm{ClaC}$ neurons held at -70 $\mathrm{mV}$ while inhibitory outward currents were recorded with $\mathrm{ClaC}$ cells held at $0 \mathrm{mV}$. In addition to excitatory currents, all ClaC cells tested showed inhibitory currents following optogenetic stimulation of cortical afferents (Fig. 7D). Several lines of evidence
B

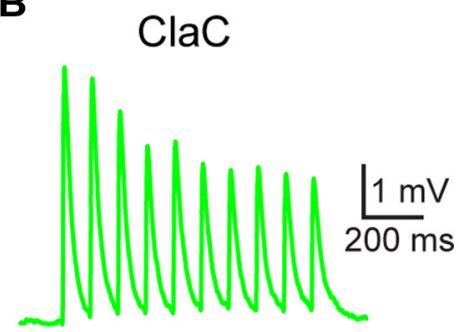

| | | | | | | | | |
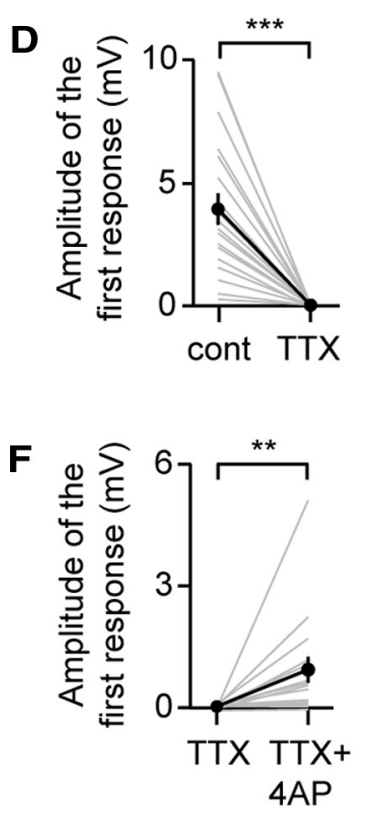

Figure 5. Corticoclaustral axons form monosynaptic connections onto ClaC cells. $A$, Experimental configuration with corticoClaustral afferents expressing ChR2 (blue) and retrogradely labeled ClaC neurons (green). $\boldsymbol{B}$, Short-latency responses recorded in a Conses are eliminated with bath application of the sodium channel blocker TTX. This is a different neuron from the one shown , Summary data showing that bath application of TTX eliminated the responses in $\mathrm{ClaC}$ neurons following optogenetic axons and a $\mathrm{ClaC}$ neuron. This recording is from the same $\mathrm{ClaC}$ neuron shown in $\mathbf{C} . \boldsymbol{F}$, Summary data showing the monosynaptic responses in ClaC neurons to cortical input following bath application of 4-AP and TTX ( $n=16, p=0.004$, sign test).

indicate that these inhibitory currents result from a disynaptic circuit. First, these inhibitory currents were eliminated following bath application of the glutamate receptor blockers NBQX and CPP (control: $278.3 \pm 106.0 \mathrm{pA}$; CPP+NBQX: $-6.7 \pm 3.2 \mathrm{pA}$, $n=3$ cells). Second, the inhibitory responses had significantly longer latencies than the short-latency monosynaptic excitatory responses generated from optogenetic activation of corticoclaustral axons (Fig. $7 D, E$ ). Third, we did not detect inhibitory responses following optogenetic activation of corticoclaustral terminals in the presence of 4-AP and TTX. Together, these findings indicate that $\mathrm{ClaC}$ neurons receive strong disynaptic feedforward inhibition as well as direct monosynaptic excitation driven by cortical input, and that PV neurons may play an important role in this inhibition.

\section{Discussion}

Here, we determined the functional connectivity of ClaC projection neurons and PV neurons within the claustrum (Fig. 8). We show that $\mathrm{ClaC}$ neurons are rarely synaptically connected with 
A

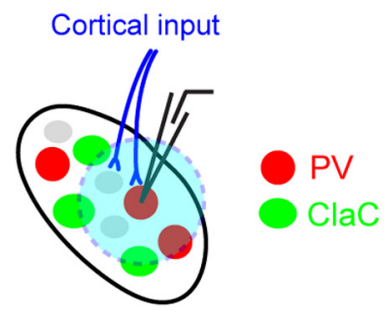

B

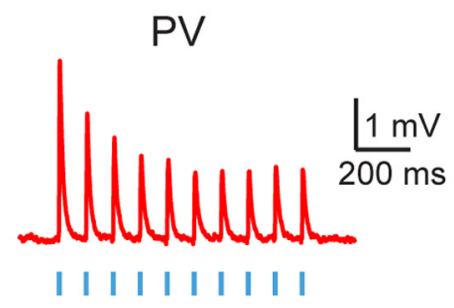

C

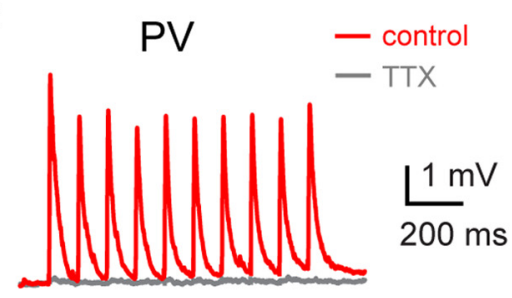

| | || || | | || || | |

$\mathbf{E}$

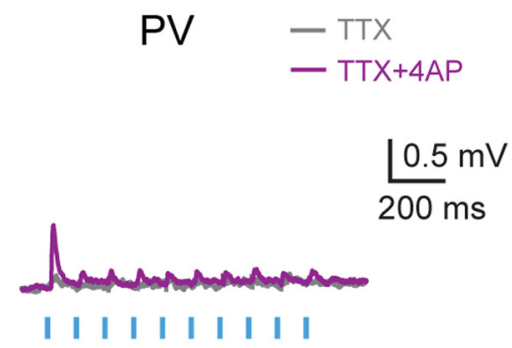

D

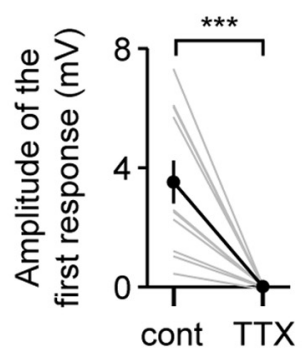

$\mathbf{F}$

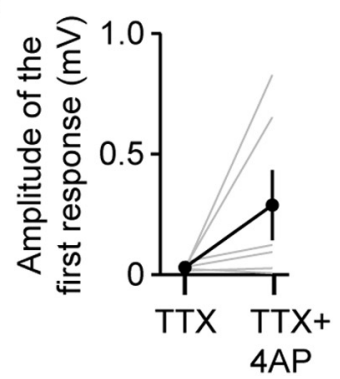

Figure 6. Corticoclaustral axons form monosynaptic connections onto PV claustral neurons. $A$, Experimental configuration. $\boldsymbol{B}$, An example recording showing short-latency postsynaptic responses recorded in a PV neuron following optogenetic stimulation of corticoclaustral axons. C, An example recording showing that these short-latency responses are eliminated with bath application of TTX. This recording is from a different neuron than the one shown in $\boldsymbol{B}$. D, Summary data showing that bath application of TTX eliminated the responses in claustral PV neurons following optogenetic activation of cortical input $(n=11, p=0.00098$, sign test). $\boldsymbol{E}$, An example recording showing that bath application of the potassium channel blocker 4-AP, in addition to TTX, reveals direct monosynaptic corticoclaustral input onto a PV neuron. This recording is from the same neuron shown in C. F, Summary data showing the monosynaptic responses to cortical input in PV neurons following bath application of 4-AP in combination with TTX ( $n=6$ cells).

one another. In contrast, PV neurons within the claustrum are highly interconnected with both electrical and chemical synapses. In addition, we found frequent synaptic connections between ClaC neurons and PV neurons. We also demonstrate that corticoclaustral axons synapse onto both $\mathrm{ClaC}$ and PV neurons. Consistent with this circuit organization, optogenetic activation of corticoclaustral afferents generates excitatory responses as well as disynaptic inhibitory responses in ClaC neurons. Our results suggest that widespread recurrent excitatory connections within the claustrum are unlikely to integrate neuronal activity within this structure. Rather, the relationship among ClaC neurons and PV neurons as well as the feedforward inhibition evoked by cortical input are typical features of a circuit that detects or amplifies correlated cortical input (Bruno, 2011; Hu et al., 2014).

A prevailing hypothesis regarding the claustrum's function is that it plays a role in multimodal sensory integration (Pearson et al., 1982; Ettlinger and Wilson, 1990; Crick and Koch, 2005; Smythies et al., 2014a; Goll et al., 2015). Several imaging studies in humans have supported this proposal, although distinguishing responses in the claustrum from multimodal responses in the

neighboring insula remains a challenge (Hadjikhani and Roland, 1998; Banati et al., 2000; Naghavi et al., 2007). Synaptic connections among $\mathrm{ClaC}$ neurons have been proposed to integrate afferent cortical activity within the claustrum (Crick and Koch, 2005; Smythies et al., 2012, 2014b; Druga, 2014). However, we found that unitary synaptic connections between $\mathrm{ClaC}$ neurons are rare. Less than five percent of tested connections were in fact synaptically connected, making it unlikely that widespread recurrent excitatory connections among $\mathrm{ClaC}$ neurons represent a cellular substrate for crossmodal integration. We also found no evidence of electrical connections among $\mathrm{ClaC}$ neurons. Thus, recurrent excitatory connections among $\mathrm{ClaC}$ neurons are unlikely to integrate or amplify the activity of $\mathrm{ClaC}$ neurons. It is possible that some as yet undefined subset of $\mathrm{ClaC}$ neurons is recurrently connected within the claustrum. Or alternatively, it is possible that single ClaC neurons integrate input from multiple sensory modalities through convergent monosynaptic input from corticoclaustral afferents emanating from different primary sensory cortical areas. However, our results are consistent with in vivo extracellular recordings that have found little evidence for multimodal responses within the claustrum and have instead suggested that there exist distinct topographic maps within the claustrum dedicated to particular sensory modalities (Olson and Graybiel, 1980; Sherk and LeVay, 1981a,b; Remedios et al., 2010).

It has also been proposed that networks of interconnected inhibitory neurons within the claustrum play an important role in its function, although to date little evidence exists to support this hypothesis. We show here that PV inhibitory neurons, which form a dense network of processes within the claustrum in a wide variety of model organisms (Druga et al., 1993; Real et al., 2003; Hinova-Palova et al., 2007, 2014; Rahman and Baizer, 2007), are highly interconnected with both chemical and electrical synapses. Interestingly, we found that the average coupling coefficient among claustral PV neurons was high (5.7\%) in our recordings, indicating that these electrical connections are not limited to juveniles (Galarreta and Hestrin, 2002). In addition to frequent $\mathrm{PV} \rightarrow \mathrm{PV}$ connections, we show that $\mathrm{ClaC}$ neurons and PV neurons were also highly interconnected with chemical synapses. This synaptic organization is similar to that described for cortical PV neurons (Galarreta and Hestrin, 1999; Gibson et al., 1999), where it has been shown that they play important roles in coordinating the activity of principal neurons (Galarreta and Hestrin, 2001; Bartos et al., 2007; Cardin et al., 2009; Sohal et al., 2009).

In the cortex, PV neuron networks play a role in synchronizing the activity of cortical projection neurons and in generating brain rhythms, including gamma oscillations in the cortex (Galarreta and Hestrin, 2001; Bartos et al., 2007; Cardin et al., 
2009; Sohal et al., 2009). A similar function could be performed here in response to cortical and other inputs to the claustrum. However, networks of electrically connected cells can also desynchronize network activity (Vervaeke et al., 2010). Modulation of the GABAergic connections among PV cells by one of the many neuromodulators enriched in the claustrum could alter the properties of this network such that, for example, brief bursts of cortical input could synchronize or desynchronize local networks of claustral neurons, depending on the behavioral state of the animal (Connors et al., 2010; Baizer, 2014; Goll et al., 2015).

This circuit organization may function to coordinate the activity of functionally related cortical regions within or across cortical hemispheres (Smith et al., 2012; Smythies et al., 2012; Smith and Alloway, 2014; Zingg et al., 2014). First, some ClaC neurons have axons that project to more than one cortical area (Bullier et al., 1984; Minciacchi et al., 1985; Li et al., 1986; Smith et al., 2012; Smith and Alloway, 2014). Second, in some regions of the claustrum, functionally related $\mathrm{ClaC}$ neurons that project to different cortical areas may be closely intermingled (Smith et al., 2012; Smith and Alloway, 2014). In both cases, coordinated activity within local groups of $\mathrm{ClaC}$ neurons could coordinate the activity of functionally related cortical areas (Smythies et al., 2012, 2014b; Reser et al., 2014; Goll et al., 2015). Networks of interconnected inhibitory neurons within the claustrum could serve to coordinate the activity of these ClaC neurons or synchronize oscillations within claustral microcircuits as PV inhibitory neurons do in the cortex (Bartos et al., 2007; Cardin et al., 2009; Sohal et al., 2009). Whether this coordinated activity can include $\mathrm{ClaC}$ neurons that project to different cortical targets remains to be tested. Much still needs to be understood regarding the topography of the claustrum's projections as the relationship between the targets of corticoclaustral axons and ClaC axons is likely complex. Thus, the impact of these effects may vary widely based on the specific projection patterns (Pearson et al., 1982; Smith et al., 2012; Smith and Alloway, 2014).

We also showed that optogenetic activation of corticoclaustral afferents generates disynaptic inhibition in $\mathrm{ClaC}$ neurons. We demonstrated that both $\mathrm{ClaC}$ and $\mathrm{PV}$ cells receive direct monosynaptic inputs from corticoclaustral axons, which is consistent with previous anatomical findings. In paired recordings, we showed that the average response to corticoclaustral input was larger in PV neurons than in $\mathrm{ClaC}$ cells, and optogenetic activation of corticoclaustral afferents generated disynaptic inhibition in $\mathrm{ClaC}$ neurons. These synaptic relationships serve to narrow the temporal window for effective integration of corticoclaustral excitation (Bruno, 2011; Hu et al., 2014). Furthermore, although the input resistance of PV neurons was significantly less than for $\mathrm{ClaC}$ neurons, the resting membrane potential of PV neurons was significantly depolarized compared with that of ClaC neurons, and the spike threshold was significantly lower in PV neurons than in $\mathrm{ClaC}$ neurons (Table 1). These factors may also contribute to the generation of feedforward inhibition by $\mathrm{PV}$
B
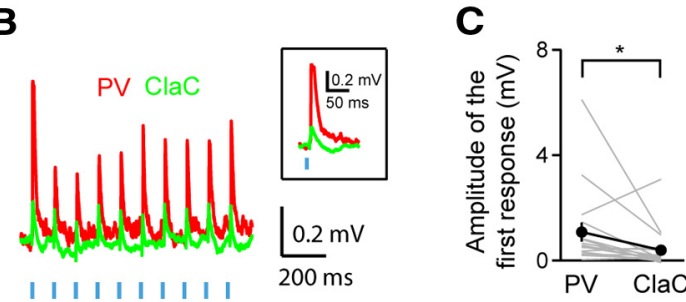

$\mathbf{E}$

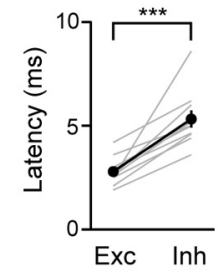

Figure 7. Cortical input evokes feedforward inhibition in $\mathrm{ClaC}$ neurons. $A$, Experimental configuration showing retrogradely inward component measured at $-70 \mathrm{mV}$ and the outward component measured at $0 \mathrm{mV}$. The latency was significantly longer for the outward component (inward: $2.79 \pm 0.21 \mathrm{~ms}$; outward: $5.33 \pm 0.41 \mathrm{~ms}, n=10$ cells, $p=0.0003$, paired $t$ test).

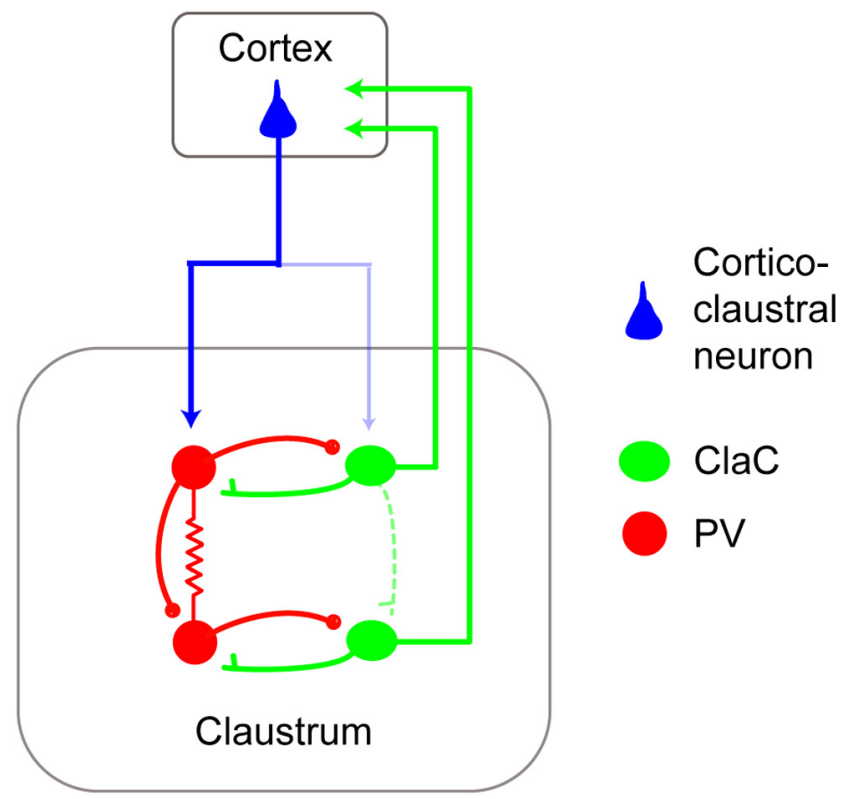

Figure 8. Schematic summarizing the circuit organization of the claustrum. ClaC (green) neurons form rare synaptic connections with other ClaC neurons while PV (red) claustral neurons are highly interconnected with both chemical and electrical synapses. Connections from ClaC neurons to PV neurons and from PV neurons to ClaCneurons are also common. Although corticoclaustral axons form monosynaptic connections onto both ClaC neurons and PV neurons, the cortical input to PV neurons is stronger. Following optogenetic activation of corticoclaustral axons, ClaC neurons show both monosynaptic excitatory responses and disynaptic inhibitory responses.

neurons in the claustrum, although the precise mechanisms must be further explored (Hu et al., 2014). This circuit organization detects correlated cortical input and could support the claustrum's proposed role in detecting salient stimuli (Remedios et al., 
2010; Goll et al., 2015). Furthermore, the claustrum's extensive connections with motor and higher-order regions of the cortex suggest that its function is not limited to sensory systems (Smith et al., 2012; Druga, 2014; Smith and Alloway, 2014; Zingg et al., 2014; Goll et al., 2015). Together, our results suggest that the organization of local circuits within the claustrum is tuned to detecting and amplifying correlated cortical input and coordinating the activity of $\mathrm{ClaC}$ neurons through networks of interconnected PV neurons. Depending on the source of afferent corticoclaustral axons targeting $\mathrm{ClaC}$ cells, single $\mathrm{ClaC}$ neurons may integrate cortical inputs from different sensory modalities. Our results are also consistent with the claustrum's proposed role in detecting salient sensory stimuli or in amplifying correlated cortical inputs to coordinate the activity of functionally related cortical regions.

\section{References}

Baizer JS (2014) The neurochemical organization of the claustrum. In: The claustrum: structural, functional and clinical neuroscience (Smythies JR, Edelstein LR, Ramachandran VS, eds), pp 85-118. San Diego: Elsevier.

Banati RB, Goerres GW, Tjoa C, Aggleton JP, Grasby P (2000) The functional anatomy of visual-tactile integration in man: a study using positron emission tomography. Neuropsychologia 38:115-124. CrossRef Medline

Bartos M, Vida I, Jonas P (2007) Synaptic mechanisms of synchronized gamma oscillations in inhibitory interneuron networks. Nat Rev Neurosci 8:45-56. CrossRef Medline

Braak H, Braak E (1982) Neuronal types in the claustrum of man. Anat Embryol (Berl) 163:447-460. CrossRef Medline

Brand S (1981) A serial section Golgi analysis of the primate claustrum. Anat Embryol (Berl) 162:475-488. CrossRef Medline

Brown SP, Hestrin S (2009a) Intracortical circuits of pyramidal neurons reflect their long-range axonal targets. Nature 457:1133-1136. CrossRef Medline

Brown SP, Hestrin S (2009b) Cell-type identity: a key to unlocking the function of neocortical circuits. Curr Opin Neurobiol 19:415-421. CrossRef Medline

Bruno RM (2011) Synchrony in sensation. Curr Opin Neurobiol 21: 701-708. CrossRef Medline

Bullier J, Kennedy H, Salinger W (1984) Bifurcation of subcortical afferents to visual areas 17, 18, and 19 in the cat cortex. J Comp Neurol 228:309328. CrossRef Medline

Calvert GA (2001) Crossmodal processing in the human brain: insights from functional neuroimaging studies. Cereb Cortex 11:1110-1123. CrossRef Medline

Cardin JA, Carlén M, Meletis K, Knoblich U, Zhang F, Deisseroth K, Tsai LH, Moore CI (2009) Driving fast-spiking cells induces gamma rhythm and controls sensory responses. Nature 459:663-667. CrossRef Medline

Chattopadhyaya B, Di Cristo G, Higashiyama H, Knott GW, Kuhlman SJ, Welker E, Huang ZJ (2004) Experience and activity-dependent maturation of perisomatic GABAergic innervation in primary visual cortex during a postnatal critical period. J Neurosci 24:9598-9611. CrossRef Medline

Connors BW, Zolnik TA, Lee SC (2010) Enhanced functions of electrical junctions. Neuron 67:354-356. CrossRef Medline

Crick FC, Koch C (2005) What is the function of the claustrum? Philos Trans R Soc B Biol Sci 360:1271-1279. CrossRef Medline

Druga R (2014) The structure and connections of the claustrum. In: The claustrum: structural, functional and clinical neuroscience (Smythies J, Edelstein LR, Ramachandran VS, eds), pp 29-84. San Diego: Elsevier.

Druga R, Chen S, Bentivoglio M (1993) Parvalbumin and calbindin in the rat claustrum: an immunocytochemical study combined with retrograde tracing from frontoparietal cortex. J Chem Neuroanat 6:399-406. CrossRef Medline

Edelstein LR, Denaro FJ (2004) The claustrum: a historical review of its anatomy, physiology, cytochemistry and functional significance. Cell Mol Biol (Noisy-le-grand) 50:675-702. Medline

Ettlinger G, Wilson WA (1990) Cross-modal performance: behavioural processes, phylogenetic considerations and neural mechanisms. Behav Brain Res 40:169-192. CrossRef Medline
Franklin KBJ, Paxinos G (2007) The mouse brain in stereotaxic coordinates. New York: Academic.

Galarreta M, Hestrin S (1999) A network of fast-spiking cells in the neocortex connected by electrical synapses. Nature 402:72-75. CrossRef Medline

Galarreta M, Hestrin S (2001) Spike transmission and synchrony detection in networks of GABAergic interneurons. Science 292:2295-2299. CrossRef Medline

Galarreta M, Hestrin S (2002) Electrical and chemical synapses among parvalbumin fast-spiking GABAergic interneurons in adult mouse neocortex. Proc Natl Acad Sci U S A 99:12438-12443. CrossRef Medline

Gibson JR, Beierlein M, Connors BW (1999) Two networks of electrically coupled inhibitory neurons in neocortex. Nature 402:75-79. CrossRef Medline

Goll Y, Atlan G, Citri A (2015) Attention: the claustrum. Trends Neurosci 38:486-495. CrossRef Medline

Hadjikhani N, Roland PE (1998) Cross-modal transfer of information between the tactile and the visual representations in the human brain: a positron emission tomographic study. J Neurosci 18:1072-1084. Medline

Hestrin S, Galarreta M (2005) Electrical synapses define networks of neocortical GABAergic neurons. Trends Neurosci 28:304-309. CrossRef Medline

Hinova-Palova DV, Paloff AM, Usunoff KG, Dimova RN, Yossifov TY, Ivanov DP (1988) Reciprocal connections between the claustrum and the auditory cortical fields in the cat. An experimental study using lightand electron microscopic anterograde degeneration methods, and the horseradish peroxidase retrograde axonal transport. J Hirnforsch 29: 255-278. Medline

Hinova-Palova DV, Edelstein LR, Paloff AM, Hristov S, Papantchev VG, Ovtscharoff WA (2007) Parvalbumin in the cat claustrum: ultrastructure, distribution and functional implications. Acta Histochemica 109: 61-77. CrossRef Medline

Hinova-Palova DV, Edelstein L, Landzhov BV, Braak E, Malinova LG, Minkov M, Paloff A, Ovtscharoff W (2014) Parvalbumin-immunoreactive neurons in the human claustrum. Brain Struct Funct 219: 1813-1830. CrossRef Medline

Hippenmeyer S, Vrieseling E, Sigrist M, Portmann T, Laengle C, Ladle DR, Arber S (2005) A developmental switch in the response of DRG neurons to ETS transcription factor signaling. PLoS Biol 3:e159. CrossRef Medline

Hu H, Gan J, Jonas P (2014) Interneurons. Fast-spiking, parvalbumin (+) GABAergic interneurons: from cellular design to microcircuit function. Science 345:1255263. CrossRef Medline

Jackman SL, Beneduce BM, Drew IR, Regehr WG (2014) Achieving highfrequency optical control of synaptic transmission. J Neurosci 34: 7704-7714. CrossRef Medline

Juraniec J, Narkiewica O, Wrzolkowa T (1971) Axon terminals in the claustrum of the cat: an electron microscope study. Brain Res 35:277-282. CrossRef Medline

Katz LC (1987) Local circuitry of identified projection neurons in cat visual cortex brain slices. J Neurosci 7:1223-1249. Medline

Kim J, Matney CJ, Blankenship A, Hestrin S, Brown SP (2014) Layer 6 corticothalamic neurons activate a cortical output layer, layer $5 \mathrm{a}$. J Neurosci 34:9656-9664. CrossRef Medline

Kowianski P, Dziewiatkowski J, Kowianska J, Morys J (1999) Comparative anatomy of the claustrum in selected species: a morphometric analysis. Brain Behav Evol 53:44-54. CrossRef Medline

Kowiański P, Timmermans JP, Moryś J (2001) Differentiation in the immunocytochemical features of intrinsic and cortically projecting neurons in the rat claustrum-combined immunocytochemical and axonal transport study. Brain Res 905:63-71. CrossRef Medline

Krook-Magnuson E, Varga C, Lee SH, Soltesz I (2012) New dimensions of interneuronal specialization unmasked by principal cell heterogeneity. Trends Neurosci 35:175-184. CrossRef Medline

LeVay S, Sherk H (1981) The visual claustrum of the cat. I. Structure and connections. J Neurosci 1:956-980. Medline

Li LY, Li YT, Zhou M, Tao HW, Zhang LI (2013) Intracortical multiplication of thalamocortical signals in mouse auditory cortex. Nat Neurosci 16:1179-1181. CrossRef Medline

Li YT, Ibrahim LA, Liu BH, Zhang LI, Tao HW (2013) Linear transformation of thalamocortical input by intracortical excitation. Nat Neurosci 16:1324-1330. CrossRef Medline

Li ZK, Takada M, Hattori T (1986) Topographic organization and collater- 
alization of claustrocortical projections in the rat. Brain Res Bull 17: 529-532. CrossRef Medline

Lien AD, Scanziani M (2013) Tuned thalamic excitation is amplified by visual cortical circuits. Nat Neurosci 16:1315-1323. CrossRef Medline

Madisen L, Zwingman TA, Sunkin SM, Oh SW, Zariwala HA, Gu H, Ng LL, Palmiter RD, Hawrylycz MJ, Jones AR, Lein ES, Zeng H (2010) A robust and high-throughput Cre reporting and characterization system for the whole mouse brain. Nat Neurosci 13:133-140. CrossRef Medline

Madisen L, Mao T, Koch H, Zhuo JM, Berenyi A, Fujisawa S, Hsu YW, Garcia AJ 3rd, Gu X, Zanella S, Kidney J, Gu H, Mao Y, Hooks BM, Boyden ES, Buzsáki G, Ramirez JM, Jones AR, Svoboda K, Han X, et al. (2012) A toolbox of Cre-dependent optogenetic transgenic mice for light-induced activation and silencing. Nat Neurosci 15:793-802. CrossRef Medline

Mathur BN (2014) The claustrum in review. Front Syst Neurosci 8:48. CrossRef Medline

Milardi D, Bramanti P, Milazzo C, Finocchio G, Arrigo A, Santoro G, Trimarchi F, Quartarone A, Anastasi G, Gaeta M (2015) Cortical and subcortical connections of the human claustrum revealed in vivo by constrained spherical deconvolution tractography. Cereb Cortex 25:406-414. CrossRef Medline

Minciacchi D, Molinari M, Bentivoglio M, Macchi G (1985) The organization of the ipsilateral and contralateral claustrocortical system in rat with notes on the bilateral claustrocortical projections in cat. Neuroscience 16:557-576. CrossRef Medline

Naghavi HR, Eriksson J, Larsson A, Nyberg L (2007) The claustrum/insula region integrates conceptually related sounds and pictures. Neurosci Lett 422:77-80. CrossRef Medline

Olson CR, Graybiel AM (1980) Sensory maps in the claustrum of the cat. Nature 288:479-481. CrossRef Medline

Pearson RC, Brodal P, Gatter KC, Powell TP (1982) The organization of the connections between the cortex and the claustrum in the monkey. Brain Res 234:435-441. CrossRef Medline

Petreanu L, Mao T, Sternson SM, Svoboda K (2009) The subcellular organization of neocortical excitatory connections. Nature 457:1142-1145. CrossRef Medline

Rahman FE, Baizer JS (2007) Neurochemically defined cell types in the claustrum of the cat. Brain Res 1159:94-111. CrossRef Medline

Real MA, Dávila JC, Guirado S (2003) Expression of calcium-binding proteins in the mouse claustrum. J Chem Neuroanat 25:151-160. CrossRef Medline

Remedios R, Logothetis NK, Kayser C (2010) Unimodal responses prevail within the multisensory claustrum. J Neurosci 30:12902-12907. CrossRef Medline

Remedios R, Logothetis NK, Kayser C (2014) A role of the claustrum in auditory scene analysis by reflecting sensory change. Front Syst Neurosci 8:44. CrossRef Medline

Reser DH, Richardson KE, Montibeller MO, Zhao S, Chan JM, Soares JG, Chaplin TA, Gattass R, Rosa MG (2014) Claustrum projections to prefrontal cortex in the capuchin monkey (Cebus apella). Front Syst Neurosci 8:123. CrossRef Medline

Sherk H, LeVay S (1981a) Visual claustrum: topography and receptive field properties in the cat. Science 212:87-89. CrossRef Medline

Sherk H, LeVay S (1981b) The visual claustrum of the cat. III. Receptive field properties. J Neurosci 1:993-1002. Medline

Shibuya H, Yamamoto T (1998) Electrophysiological and morphological features of rat claustral neurons: An intracellular staining study. Neuroscience 85:1037-1049. CrossRef Medline

Sloniewski P, Usunoff KG, Pilgrim C (1986) Retrograde transport of fluorescent tracers reveals extensive ipsi- and contralateral claustrocortical connections in the rat. J Comp Neurol 246:467-477. CrossRef Medline

Smith JB, Alloway KD (2010) Functional specificity of claustrum connections in the rat: interhemispheric communication between specific parts of motor cortex. J Neurosci 30:16832-16844. CrossRef Medline

Smith JB, Alloway KD (2014) Interhemispheric claustral circuits coordinate sensory and motor cortical areas that regulate exploratory behaviors. Front Syst Neurosci 8:93. CrossRef Medline

Smith JB, Radhakrishnan H, Alloway KD (2012) Rat claustrum coordinates but does not integrate somatosensory and motor cortical information. J Neurosci 32:8583-8588. CrossRef Medline

Smythies J, Edelstein L, Ramachandran V (2012) Hypotheses relating to the function of the claustrum. Front Integr Neurosci 6:53. CrossRef Medline

Smythies J, Edelstein L, Ramachandran V (2014a) Hypotheses relating to the function of the claustrum II: does the claustrum use frequency codes? Front Integr Neurosci 8:7. CrossRef Medline

Smythies JR, Edelstein LR, Ramachandran VS (2014b) Hypotheses relating to the function of the claustrum. In: The claustrum: structural, functional and clinical neuroscience (Smythies JR, Edelstein LR, Ramachandran VS, eds), pp 299-352. San Diego: Elsevier.

Sohal VS, Zhang F, Yizhar O, Deisseroth K (2009) Parvalbumin neurons and gamma rhythms enhance cortical circuit performance. Nature 459 : 698-702. CrossRef Medline

Vervaeke K, Lorincz A, Gleeson P, Farinella M, Nusser Z, Silver RA (2010) Rapid desynchronization of an electrically coupled interneuron network with sparse excitatory synaptic input. Neuron 67:435-451. CrossRef Medline

Zingg B, Hintiryan H, Gou L, Song MY, Bay M, Bienkowski MS, Foster NN, Yamashita S, Bowman I, Toga AW, Dong HW (2014) Neural networks of the mouse neocortex. Cell 156:1096-1111. CrossRef Medline 